\title{
VIDENCIA Y ESFERA POÉTICA EN PROSA DEL OTOÑO EN GERONA. DESFIGURACIÓN, MIGRANCIA Y DUELO EN LA POESÍA DE ROBERTO BOLAÑO*
}

\author{
CLAIRVOYANCE AND POETIC SPHERE IN PROSA DEL OTOÑO \\ EN GERONA. DESFIGURATION, MIGRATION AND MOURNING IN \\ THE POETRY OF ROBERTO BOLAÑO
}

Francisco Salas Oliva

Pontificia Universidad Católica de Chile. Santiago, Chile

ftsalas@uc.cl

\begin{abstract}
Resumen: Este artículo corresponde a una propuesta de lectura del poema Prosa del Otoño en Gerona del escritor chileno Roberto Bolaño. A través del análisis de los recursos discursivos orientados a la configuración del espacio vital y textual, nos aproximaremos a una poética que no sólo evidencia el desarraigo y la intemperie de un sujeto latinoamericano en permanente nomadía, sino que además se propone performativamente, en tanto poema/discurso, como lugar y límite de la propia experiencia literaria.
\end{abstract}

Palabras clave: Esferas, espacio, poética, videncia.

\begin{abstract}
This article corresponds to a proposal to read the poetry Prosa del Otoño en Gerona by the Chilean writer Roberto Bolaño. Through the analysis of the discussion resources oriented to the configuration of the vital and textual space, we will approach a poetics that not only evidences the uprooting and the inclemency of a Latin American subject in permanent nomady, but which also performatively proposes itself, as regards poems/discourse, as the place and limit of one's literary experience.
\end{abstract}

Keywords: Spheres, space, poetics, clairvoyance.

Recibido: 12.03.2018. Aceptado: 22.10.2018.

* Este artículo se realizó en el marco del proyecto de investigación FONDECYT Regular $\mathrm{N}^{\circ}$ 1150535, "Poema en prosa y modernidad en Chile: del modernismo a la vanguardia (1888-1945)". 
$\mathrm{N}$ o son numerosas aproximaciones críticas que hayan abordado directamente la obra poética ${ }^{1}$ de Roberto Bolaño, en efecto, esta ha quedado rezagada a partir del interés que ha suscitado su obra narrativa (novela, cuentos, incluso la crítica y el ensayo), la cual lo inserta definitivamente en el canon de la literatura hispanoamericana. Ahora bien, los trabajos de investigación que sí se han detenido en ella dividen sus aguas en dos vertientes bastante reconocibles, por un lado aparecen aquellas que consideran su poesía al interior de un proyecto total, indiferenciada de su obra narrativa, asumiendo que una de las características fundamentales de la escritura de Bolaño residiría en su condición transgenérica, en el desdibujamiento de los modelos estructurales y normativos del discurso que, de paso, posicionarían a la obra de R. B. en el establo de las llamadas literaturas postmodernas. Despachando los lindes genéricos, esta crítica habla de un proyecto total de escritura pasando por alto, incluso, las propias distinciones que Bolaño establecía para su trabajo. Por otra parte, aparece una crítica que reconoce en el Bolaño poeta a un escritor que al optar por la ruptura y transgresión de los marcos que sitúan las convenciones heredadas de manera crítica y decisiva por la tradición moderna respecto al género lírico, aun en sus manifestaciones contemporáneas, productiviza una escritura que termina, de todas formas, subordinándose al "género narrativo" como eje o espacio textual múltiple, tanto en el plano referencial (la inserción de la metaficción, la poesía y los poetas como temática de sus obras) como formal (el registro del delirio, la prosa poética, dispositivos retóricos de herencia vanguardista). Sin despacharlas del todo, creemos que se hace necesario profundizar los aspectos que conectan las diversas textualidades que componen la obra de Bolaño, sobre todo precisar las características o el carácter que imponen tales disposiciones en una obra poética. La ocasión de proponer una lectura de uno de sus poemas nos permitirá, ciertamente, avanzar hacia ese objetivo.

En 1977 y con 24 años Roberto Bolaño llega a Europa para instalarse

${ }^{1}$ En primera instancia y con miras a un deslinde absolutamente provisorio, me refiero aquí a aquellas discursividades que se publicaron bajo la denominación de poema, poemas y/o poesía. En esa línea quisiera destacar los trabajos críticos de Patricia Espinosa, Nibaldo Acero, Jaime Blume, Luis Bagué Quílez, Rubén Medina, Matías Ayala, Jorge Morales, Adriana Castillo Berchenko, Ignacio Echevarría, Helena Usandizaga y Andrea Cobas Carral. 
precariamente en Barcelona. Atrás ha quedado el México de su adolescencia, instancia de producción e interacción literaria junto al movimiento que él mismo fundara con el poeta Mario Santiago Papasquiaro, los infrarrealistas. Más atrás aún, el Chile de la infancia, y la fantasmal república que cayó bajo el Golpe Militar de 1973, espacio que de manera casi definitiva pasaría a convertirse en poco más que una grieta habitada por fantasmas.

Los últimos años de la década del setenta constituyen la prueba de sobrevivencia para un proyecto escritural aún en formación, una escritura que comienza a reflexionar sobre sí misma, profundamente marcada por un contexto vital de precariedad material y nomadismo incesante. Con posterioridad, el escritor no dejará de mencionar dicha etapa y convertirla en un referente autoficcional permanente de su obra. "En aquella época yo tenía veintitantos años y era más pobre que una rata. Vivía en las afueras de Girona, en una casa en ruinas que me habían dejado mi hermana y mi cuñado tras marcharse a México y acababa de perder un trabajo de vigilante nocturno en un camping de Barcelona”, leemos en las primeras líneas de Sensini, del volumen de relatos Llamadas telefónicas (Bolaño, 1997: 6).

Es en ese contexto que Prosa del Otoño en Gerona corresponde a la producción literaria de un Bolaño recientemente instalado en la ciudad catalana "está escrito en 1981 durante mi primer año de estancia en la ciudad tres (¿̇o dos?) veces inmortal” (Bolaño, 2007: 443). En efecto, si bien su primera aparición es en el volumen titulado Fragmentos de la Universidad Desconocida (Bolaño, 1992), la segunda, aún más tardía, al interior del poemario Tres (Bolaño, 2000) y finalmente de manera póstuma en La Universidad Desconocida (Bolaño, 2007); se desprende de los cuadernos de notas fechados y las declaraciones del propio autor que la producción del poema partiría a finales de 1979 y concluiría en el año 1981.

En Prosa del Otoño en Gerona Bolaño anuncia ya desde el título una opción formal de al menos 150 años de tradición, el modo escritural de la prosa poética que, cultivada por algunos autores románticos en la primera mitad del siglo XIX, se abre definitivamente en 1862 con El spleen de París de Charles Baudelaire, que como bien señala el filósofo Pablo Oyarzún en la nota preliminar de su propia traducción: "rompe con lo que hasta el momento sostenía la condición definitoria de lo poético en la teoría y la práctica heredadas, vale decir, el momento de la forma” (2008: 7). Prosa del Otoño en Gerona está compuesto por 35 fragmentos en prosa, sin 
título, que si bien no logran del todo funcionar autónomamente, ofrecen en el decurso de su lectura una compleja cohesión intra e intertextual; y es que el poema de Bolaño, efectivamente, es un "espacio de problematización metaliteraria, el que a partir de la gama de recursos formales desplegados, abre la lectura sobre la instancia de enunciación literaria, los límites difusos entre lo real y lo imaginario, la inscripción autobiográfica, la soledad, el desarraigo del migrante latinoamericano, la videncia poética y el duelo. Postulamos acá que la poética de Bolaño dispuesta en Prosa del Otoño en Gerona constituye una instancia de territorialización existencial crítica, la construcción de un espacio literario que se resiste, desde su propia performatividad en tanto discurso, a la evidencia del vacío.

\section{La enunciación del hablante, escenario o caleidoscopio que difumina al sujeto lírico}

Uno de los aspectos más llamativos de los recursos que dispone Bolaño en Prosa del otoño en Gerona corresponde a las variantes enunciativas de la voz lírica. Al igual que Georges Perec en Un hombre que duerme (2012), el poemario se abre a la actitud apostrófica, un "tú" autoconfesional que parece referirse a sí mismo el episodio basal de la dimensión temática del texto, a saber, la angustia, el desaliento y el tedio provocado por la ruptura amorosa con la que denomina "la desconocida". Dicho "tú" se transforma en un verdadero prisma de las directrices referenciales al hablante que no hace más que multiplicarlo o bien fracturarlo:

Dice que está bien. Tú dices que estás bien y piensas que ella debe estar realmente bien y que tú estás realmente bien. Su mirada es bellísima, como si viera por primera vez las escenas que deseó toda su vida. Después llega el aliento a podrido, los ojos, aunque ella diga (mientras tú permaneces callado, como en una película muda) que el infierno no puede ser el mundo donde vive (Bolaño, 2000: 19).

El efecto que provoca dicha disposición discursiva es relevante, pues la segunda persona termina refractando de la misma forma al potencial receptor, aproxima al lector a un espejo en donde el rostro que se dibuja se constituye a partir de un juego permanente de aproximación y distancia- 
miento entre lo propio (sí mismo) y lo ajeno (el otro). El lector-espectador no es un simple voyeur que recorre la obra de modo pasivo, sino que corre el peligro de ser alcanzado por la potencialidad de un lenguaje que le aludiría. Cabe mencionar que dicho dispositivo se vuelve cada vez más complejo, ya que Bolaño articula un juego metatextual en donde el hablante-protagonista es referido como "personaje" (2000: 20), "el autor" (2000: 28) e incluso "R. B.” (2000: 29). Si consideramos que para Émile Benveniste (1971) es en el instante del discurso en que "yo" designa al locutor, donde este se enuncia como "sujeto" y surge la subjetividad en el juego literario, dicho "sujeto" en el espacio textual analizado se indetermina, renuncia a la plena autodeterminación semántica de sí para [abrirse] en haces plurales que incluyen elementos de referencia autobiográfica potenciadores del movimiento centrífugo de sentidos: "[...] el resentimiento feroz de ser lo que soy, el sueño en el ojo, la desnudez ósea de un viejo pasaporte consular expedido en México el año 73, válido hasta el 82, con permiso para residir en España durante tres meses, sin derecho a trabajar" (Bolaño, 2000: 36).

Ahora bien, ya bastante se ha hablado de la apertura e indeterminación del sujeto en la poesía que surge desde mediados del siglo XIX, lo que resta aquí, posiblemente, es señalar las implicancias que tiene dicha indeterminación a la hora de proponer una lectura del poema. En ese sentido, y desde luego por contraste, resulta interesante volver la mirada al ya clásico trabajo de Gastón Bachelard La poética del espacio (1965), pues en ella el fenomenólogo comprende a la producción poética como una instancia constructiva (performativa) por excelencia, la cual remite y busca la restitución de los espacios íntimos en tanto cobijos existenciales. Aunque es cierto que su proyecto se fija en aquellas poéticas que tienden a la topofilia, lo que no aborda o deja de abordar en sus objetivos nos posibilita una entrada al texto de Bolaño. Bachelard se preocupa de aquellas poéticas que:

Aspiran a determinar el valor humano de los espacios de posesión, de los espacios defendidos contra fuerzas adversas, de los espacios amados. Por otra parte, los espacios de hostilidad están apenas evocados en las páginas siguientes. Esos espacios del odio y del combate sólo pueden estudiarse refiriendo a materias ardientes, a las imágenes del apocalipsis (Bachelard, 1965: 28).

Pues bien, la configuración de la instancia enunciativa, la asunción de 
una subjetividad quebrada en Prosa del otoño en Gerona, al tiempo que se presenta como una palabra que se resiste a las fuerzas adversas que debe enfrentar, nos habla también de "esas materias ardientes" de esas "imágenes apocalípticas” que sitúan al límite de sus posibilidades el propio devenir humano.

La proyección del modo autobiográfico salta a la vista como un llamado al lector para recorrer ese "bios" en tensión que, en tanto discurso, se plasma como una verdadera dislocación o desdoblamiento productivo del enunciador, ya que a través del recurso de la multiplicación de los puntos de enunciación en el poema (alteridad del uso deíctico yo - tú), la idea de un sujeto que es capaz de "vaciarse" a través del lenguaje como "medio" se desecha por completo y da paso a la configuración de un hablante en tránsito, en devenir constante; uno que instala la metáfora de una identidad problematizada o resquebrajada, en sintonía con la imagen trashumante del sujeto latinoamericano que se patenta en la segunda mitad del siglo XX. Dicha configuración es precisamente la puesta en escena del "extrañamiento" del sujeto frente a su mismidad, en otras palabras, corresponde a un proceso autorreflexivo que asume la fragmentación identitaria como un proceso de desdoblamiento: "Su rostro, fragmentado alrededor de él, aparece sometido a su ojo que lo reordena, el caleidoscopio ideal. (O sea: la desesperación del amor, la piedad, etc.)” (Bolaño, 2000: 30).

Pero ¿̇qué es aquello que motiva tal desdoblamiento? En el caso de Prosa del otoño en Gerona aparecen, al menos, tres fuerzas motrices complementarias, una de naturaleza colectiva- implícita (el devenir del sujeto latinoamericano que ha sobrevivido a la experiencia destructiva de la dictadura y la muerte del sueño revolucionario), otra de naturaleza individualexplícita (la ruptura amorosa como tragedia coyuntural en un suelo extranjero) y por último la de los alcances que el propio ejercicio poético puede tener en el escenario de una experiencia dislocada. Dicha tríada se entrelaza para abrir al sujeto a su "extrañamiento", de la misma forma, cada una de ellas se constituyen como pérdidas o caídas que obligan al sujeto a volverse sobre sí mismo para advertir la intemperie a la que se expone. Ese es precisamente el "acontecimiento" que instala el poema, vale decir, una experiencia de la epifanía o videncia del poeta que no es más que el reconocimiento del vacío que se despliega ante sus ojos y la oportunidad vitalmen- 
te paradójica que le ofrece el ejercicio de documentarla en el propio poema, transformándola en alegoría o huella; de esta forma el "acontecimiento" del poema se apropia de las esquirlas de la experiencia destructiva para instalar una nueva posibilidad de resistencia vital, una respuesta simbóli$\mathrm{ca}^{2}$ ante las fuerzas apocalípticas. Esta reacción productiva es retratada por Peter Sloterdijk de la siguiente manera:

Lo que se llama fin del mundo significa estructuralmente muerte de esferas. Su caso más real a pequeña escala es la separación de los amantes, la vivienda vacía, la foto rota; en su forma general aparece como muerte de la cultura, como la ciudad quemada, el lenguaje desaparecido. La experiencia humana e histórica testifica siempre que las esferas pueden persistir más allá de la separación mortal y que lo perdido puede permanecer presente en los recuerdos como advertencia, como fantasma, como misión, como saber (Sloterdijk, 2014: 54).

La experiencia poética moderna por antonomasia es representada, así, como la advertencia vertiginosa de lo abisal: "El caleidoscopio observado. La pasión es geometría. Rombos, cilindros, ángulos latidores. La pasión es geometría que cae al abismo, observada desde el fondo del abismo" (Bolaño, 2000: 51). Lo poético (la visión del desfondo existencial) surge de dicho acontecimiento, el poema integra, a nuestro juicio, la escenificación de su registro, el choque azaroso que se ha experimentado no mediante el trabajo literario razonado, sino que a través de una experiencia vital traumática "Esta esperanza yo no la he buscado. Este pabellón silencioso de la Universidad Desconocida” (Bolaño, 2000: 52).

${ }^{2}$ De aquí en adelante entenderemos como esfera la metáfora epistemológica propuesta por el filósofo alemán Peter Sloterdijk, quien señala en la apertura de su obra del mismo nombre las motivaciones de su estudio: "El objetivo de este libro en tres volúmenes es probar que el ser-en-esferas constituye la relación fundamental para el ser humano, una relación, ciertamente, contra la que atenta desde el principio la negación del mundo interior y que ha de afirmarse, reconstituirse y crecerse continuamente frente a las provocaciones del Fuera. En este sentido las esferas son también conformaciones morfo-inmunológicas. Sólo en estructuras de inmunidad, generadoras de espacio interior, pueden los seres humanos proseguir sus procesos generacionales e impulsar sus individuaciones. Nunca han vivido los seres humanos en inmediatez a la llamada naturaleza, ni sus culturas, sobre todo han pisado jamás el suelo de lo que se llaman los hechos mismos" (Sloterdijk, 2014: 51-52. 


\section{La condición migrante del hablante en el poema, desterritorialización y devenir}

La inestabilidad antes expuesta deviene en otro de los rasgos determinantes de la configuración de la voz en Prosa del Otoño en Gerona, dicha configuración pasa por la marca abierta de un sujeto extranjero (sin tierra ni habitar) que asume la voz en el poema. Este sujeto en nomadía, aquel que ha enfrentado la diáspora política de la segunda mitad del siglo pasado en Latinoamérica, llega a un nuevo espacio que se propone como una vía alternativa de "inmunización" existencial, un invernadero cruzado en su condición extensiva (como proyecto global tras la caída de la utopía social) por la más radical y feroz de las contradicciones:

Pero quien ayuda a construir el invernadero global de la civilización cae en paradojas termopolíticas: para que su construcción se lleve a cabo -y esta fantasía espacial está en la base del proyecto globalización- ingentes cantidades de población, tanto en el centro como en la periferia, tienen que ser evacuadas de sus viejos cobijos de ilusión regional bien temperada y expuestas a las heladas de la libertad. El constructivismo total exige un precio inexorable. Para conseguir suelo libre para la esfera artificial de recambio, en todas las viejas naciones se dinamitan los restos de creencia en el mundo interior y las ficciones de seguridad, en nombre de una ilustración radical del mercado que promete mejor vida, pero lo que consigue para empezar, es reducir drásticamente los estándares de inmunidad de los proletarios y de los pueblos periféricos. De pronto, masas desespiritualizadas se encuentran a la intemperie sin que jamás se le hayan aclarado abiertamente el sentido de su destierro (Sloterdijk, 2014: 34-35).

El sujeto del poema es lúcido frente a las condiciones que impone este nuevo escenario, en su configuración nos da cuenta de su carácter de sucedáneo, para él no hay posibilidad de integrarse plenamente al interior de la cultura metropolitana que lo recibe, frente a ella se dibuja un estado de suspenso o fragilidad que se demuestra también en la omisión al pasado histórico-colectivo trágico que ha sido el punto de fuga de su nomadía: "El instante prístino que es el pasaporte de R. B. en octubre de 1981, que lo acredita como chileno con permiso para residir en España, sin trabajar, durante otros tres meses. iEl vacío donde ni siquiera cabe la náusea!" 
(Bolaño, 2000: 29). Este limbo existencial se nos presenta como una situación intermedia (el aquí-ahora frente al allá-pasado) que nunca se resuelve, de hecho ni siquiera podemos atribuirle la categorización clásica del inmigrante que sugiere el crítico Abel Trigo, según la cual "el inmigrante moderno es generalmente un sedentario que, para protegerse del dolor de la pérdida y la ansiedad por lo desconocido, procede a una disociación, ya sea denigrando el allá-entonces y exagerando su admiración por el aquíahora, o idealizando a aquél como utopía y vivificando a este último en tanto distopía" (2000: 274) pues el hablante de Prosa del otoño en Gerona no denigra el allá-entonces, ni menos eleva el aquí-ahora que experimenta como instancia fracturada. De hecho, las referencias al pasado no son más que la constatación de un estado de circunstancias presentes; la cultura, la sociedad, la ciudad de Gerona es un escenario que no permite anclas; la indiferencia de una ciudad que, si bien acepta los desplazamientos, sólo lo hace en la medida que estos se transforman en actos residuales de un verdadero "no lugar" (se trata de un espacio que posibilita la aparición de sujetos, pero no de individuos-singularidades). Por ello, sería más preciso hablar de migrancia al referirse a la condición que proyecta el hablante, ya que la verdadera dimensión de esta condición puede representarse como "un agujero negro en el tiempo y el espacio, donde da lo mismo haberse ido ayer que hace mil años, un sentimiento permanente de ajenidad como si se volviera del mundo de los muertos" (Trigo, 2000: 183). En efecto, el discurso del migrante yuxtapone lenguas y sociolectos diversos en una dinámica centrífuga, expansiva, que dispersa el lenguaje, contaminándolo con tiempos y espacios otros, con experiencias otras que lo atraviesan en múltiples direcciones mientras experimenta la ajenidad del aquí-ahora y del entonces-allá.

La dimensión espacial (o territorial) del poema se articula a través de un discurso sumario, prosaico, descripciones secas y despojadas de modalizaciones discursivas apreciativas: "Mañana de domingo. La Rambla está vacía, sólo hay algunos viejos sentados en las bancas leyendo el periódico. Por el otro extremo las siluetas de dos policías inician el recorrido" (Bolaño, 2000: 31). Los personajes que se despliegan en dicho espacio no son individualizados, pareciera que la macrorrealidad citadina del hablante se conformase a partir de lugares del anonimato, espacios que se extienden y contaminan la microrrealidad del sujeto generando la idea de un des- 
arraigo permanente: "No es de extrañar que la habitación del autor esté llena de carteles alusivos. Desnudo, da vueltas por el centro contemplando las paredes descascaradas, en las cuales asoman signos, dibujos nerviosos, frases fuera de contexto" (Bolaño, 200o: 22). Es el propio hablante quien está fuera de contexto, el espacio se deja ver en el silencio del orden que lo traza, pues no se trata aquí de la represión, la muerte y desaparición que se ejerció (y ejerce todavía) en varias ciudades latinoamericanas que estuvieron (y están) bajo dictaduras; se trata de un orden fáctico más sutil y no menos destructivo.

Este orden es caracterizado por Zigmunt Bauman, quien citando al antropólogo Claude Leví-Strauss nos señala dos de sus materializaciones ostensibles:

La primera estrategia consistía en "vomitar", expulsando a los otros considerados irremediablemente extraños y ajenos: prohibiendo el contacto físico, el diálogo, el intercambio social y todas las variedades de commercium, comensalidad o connubium. Hoy las variantes extremas de la estrategia "émica" son, como siempre, el encarcelamiento, la deportación y el asesinato. Las formas superiores y "refinadas" (modernizadas) de la estrategia "émica" son la separación espacial, los guettos urbano, el acceso selectivo a espacios y la prohibición selectiva de ocuparlos (Bauman, 2002: 109).

El hablante es ese otro sobre el cual cae el orden que rige el escenario del poema, un totalitarismo que absorbe la experiencia, busca su domesticación para fijarla y hacerla permanentemente administrable a partir de la exclusión. Creo que dicho régimen puede ser observado en la configuración del espacio degradado en el que intenta habitar el sujeto del poema, el proceso de articularlos responde a la proyección de su interioridad, en donde insisto, la ajenidad y el desarraigo son permanentes. Así, el decurso de los fragmentos que constituyen el devenir del sujeto a lo largo del texto lo desligan del pasado y el futuro, para instalarlo de modo abrupto en un eterno presente/suspenso.

Cabe precisar que la condición antes referida es reforzada en el poema por recursos discursivos específicos como la descripción fotográfica o la propia disposición de los fragmentos como si fuesen parte de un guión cinematográfico, cito en extenso el fragmento número dos: 
La desconocida está tirada en la cama. A través de escenas sin amor (cuerpos planos, objetos sadomasoquistas, píldoras y muecas de desempleados) llegas al momento que denominas el otoño y descubres a la desconocida.

En el cuarto, además del reflejo que lo chupa todo, observas piedras, lajas amarillas, arena, almohadas con pelos, pijamas abandonados. Luego desaparece todo (Bolaño, 2000: 34).

Los alcances de esta disposición son amplios, Bolaño pone énfasis en las formas y síntesis que permiten la asunción de cierta "realidad”, y escoge para ello, precisamente, mediatizaciones propias de los mass media como el cine y la fotografía; dispositivos visuales que contrastan con la posible interpelación apostrófica al lector mencionada al comienzo del artículo, pues en esas instancias más bien lo "distancia" de la "realidad" designada y lo aproxima mucho más a la propia condición formal del poema en tanto materialidad linguística. Se genera así un efecto de hiperrealidad que permite un modo de relación fluctuante y paradójico con el texto, en alerta permanente frente a un espacio que se vive como extraño, como otro, como un "no lugar". La experiencia de lo hiperreal es otra de las formas en que el desarraigo se articula, esta se propone como la forma de un desplazamiento sobre un tiempo-espacio alterno, como si fuese dentro de un film; así el lector asume el mundo del poema como el despliegue de un decorado, que lo hace pensar en la propia "realidad" que lo constituye, y desde luego en las estrategias mediáticas similares que condicionan también su propia contingencia. Resultado paradójico para el lector, pues aparece una empatía (o reconocimiento) por la representación del mundo, al tiempo que surge la ajenidad y la no pertenencia frente a sus efectos.

Esta posición desterritorializada ha sido atribuida como una constante en la producción de Roberto Bolaño, posición que es coherente a la experiencia vital que el mismo ha declarado como fructífera:

[...] Por otra parte, siempre me ha parecido absurdo dividir a los escritores españoles de los latinoamericanos. Tal vez esto si lo digo yo es un poco fácil porque yo no soy propiamente latinoamericano. Yo he vivido muchísimos años en España. Yo aquí me siento extranjero, eso sin ninguna duda. De hecho, cuando estoy en Latinoamérica todo el mundo me dice: <<Pero si tú eres español >>, porque para ellos hablo como un español. Para un español, no. Un español ve claramente que yo soy un 
sudamericano. Y ese estar en el medio, no ser ni latinoamericano ni español, a mí me pone en un territorio bastante cómodo, en donde puedo fácilmente sentirme tanto de un lado como de otro" (Bolaño, 2000: 64).

\section{Prosa del otoño en Gerona, la imagen del duelo permanente en la experiencia literaria}

Quisiera volver sobre uno de los aspectos centrales de Prosa del otoño en Gerona, insistir en que la obra representa la experiencia vidente de la poesía moderna, particularizarla como un movimiento que depende de la poética que se dibuja explícitamente en el texto a través de recursos metaliterarios:

Al despertar pienso que la luminosidad del arte asumido y reconocido en plena juventud es algo que de una manera absoluta se ha alejado de mí. Cierto, estuve dentro del paraíso, como observador o como náufrago, allí donde el paraíso tenía la forma del laberinto, pero jamás como ejecutante (Bolaño, 2000: 34).

En efecto, si en el plano referencial se plantea un estado existencial en donde la experiencia artística se niega o al menos ha quedado en el pasado, en el plano discursivo y performativo el poema sigue constituyéndose, se materializa en una zona confidencial y autobiográfica. El hablante caracteriza la esfera artístico-poética como una dimensión imposible de alcanzar por la vía razonada, ser poeta por el sólo acto de escribir poemas ha constituido una derrota, lo que no impide que lo logre por una vía aún más potente, la de la propia experiencia vital en tanto videncia. Los ecos de dicha videncia resuenan en la poesía moderna en nuestra lengua, como tara aparece la poesía nerudiana que impulsó un "continuum" y una respuesta al mandato de Arthur Rimbaud respecto a la videncia del poeta y su propio camino a través del desajuste razonado de los sentidos, sobre todo en sus Residencias. Ahora bien, la experiencia que signa el poema de Bolaño no sólo mantiene una relación de alteridad con dicha concepción del ejercicio poético, pues también se distancia en la medida que la experiencia vidente de Prosa del otoño en Gerona no constituye una instancia profética o mesiánica, por el contrario, es un acontecimiento saturado por la intimidad 
y el anonimato, por la imposibilidad de ingresar en el perfil de una comunicación o comunión positiva. El hablante-poeta registra paralelamente la búsqueda del escritor en formación (que no deviene en videncia alguna) y es el trauma amoroso-histórico y personal lo que sí lo lleva a la experiencia directa de lo poético (las resonancias con la concepción romántica de la poesía como una disposición particular y abarcadora de la vida se hacen aquí evidentes). Es ahí donde desaparece la mediatización y en su reemplazo surge el desfondamiento de una realidad que se abre a otra absolutamente desconocida. $\mathrm{Al}$ exponer la proximidad de lo indeterminado se experimenta la propia muerte, frente a la vastedad o infinito de lo revelado el hablante se recoge y reconoce sus límites y la representación que hace de la experiencia en el discurso poético podría constituir el ciclo del duelo; el mismo Bolaño lo plantea al final de otro poema (Gente que se aleja) "De lo perdido, de lo irremediablemente perdido, sólo deseo recuperar la disponibilidad cotidiana de mi escritura líneas capaces de cogerme del pelo y levantarme cuando mi cuerpo ya no quiera aguantar más" (Bolaño, 2007: 242).

La aparición del duelo (lo poético que reside en él) depende del vacío, la constitución de una forma que se exige hasta el punto de su imposibilidad. La palabra poética obliga a su practicante a vivir de cara a la muerte, pues paradojalmente dicha instancia infranqueable determina todo principio creativo, no sólo a nivel estético, sino por sobre todo, en el sentido de su habitar poético. Martín Heidegger en Arte y Poesía al hablar del poeta señala que es un hombre "proyectado fuera" (2006: 108); si despojamos dicha declaración de sus alcances metafísicos (como lo hace el propio Sloterdijk por ejemplo), esto implicaría que el poeta de la modernidad se desprende de los imaginarios protectores, restauradores del control y las certezas; aun el poeta contemporáneo, quien sigue abriéndose a lo indeterminado, continuará en la búsqueda y registro constante de la singularidad acontecimental, que en el caso de Bolaño, si bien se reconoce como infructuosa, es igualmente exigente de una determinada ética, imposible de eludir una vez que ha sido experimentada, una vida a la intemperie, cito en extenso:

La realidad. De alguna manera que no podría explicar la casa parecía tocada por algo que no tenía en el momento de ausentarme. Las cosas parecían más claras, por ejemplo, mi sillón me parecía claro, brillante, y la cocina, aunque llena de polvo pegado a costras de grasa, daba una 
impresión de blancura, como si se pudiera ver a través de ella. (¿Ver qué? Nada, más blancura.) De la misma manera, las cosas eran más excluyentes. La cocina era la cocina y la mesa era sólo la mesa. Algún día intentaré explicarlo, pero si entonces, a los dos días de haber regresado, ponía las manos o los codos sobre la mesa, experimentaba un dolor agudo, como si estuviera mordiendo algo irreparable (Bolaño, 2000: 48).

La percepción del hablante nos muestra una realidad mudable, constata en el discurso poético el devenir de las cosas, de una "realidad" que es extraña e imposible de "explicar", sólo queda la expresividad propia del lirismo, el "dolor agudo", la sensación de estar "mordiendo algo irreparable".

En este punto lo que nos transmite el hablante es la experiencia del shock, es decir, el desfondamiento de la realidad que se ha abierto con el poema. A propósito de ello, el filósofo italiano Gianni Vattimo en su ensayo El arte de la oscilación (1990) ha señalado que el "sentido del ser" de nuestra época se anuncia y anticipa de manera particularmente evidente en la experiencia estética y para sostener esta tesis acude al clásico ensayo de Walter Benjamin sobre arte en la época de su reproductibilidad técnica, poniendo énfasis, esta vez, sobre la idea de que las nuevas condiciones de reproducción y goce artístico que se dan en las sociedades de los mass media han modificado de modo sustancial la esencia, el wesen de arte, que en el sentido Heideggeriano correspondería a la forma de "darse" que tiene el arte en la época actual. Vattimo plantea que frente a la automatización que genera la recepción general de los medios masivos y frente a la dominante perspectiva de una comunicación instrumental (como acicate ubicuo e intensivo de respuestas mensurables y capitalizables), la experiencia estética constituye una posible apertura a través del desarraigo existencial que esta potencialmente puede provocar. Vattimo plantea, en síntesis, que la experiencia del shock tiene que ver con la muerte:

[...] la muerte como posibilidad constitutiva de la existencia, el hecho de que la obra sea en vez de no ser. El hecho de ser, está en la base de la experiencia existencial de la angustia, estado emocional que experimenta el hombre cuando se enfrente al hecho desnudo de estar arrojado en el mundo. La angustia registra la insignificancia, la gratuidad fatal que hay en el hecho de que el mundo sea. La experiencia del desarraigo (Vattimo, 1990: 140). 
Doble movimiento entonces, pues desde esta perspectiva el poema de Bolaño no sólo refiere una experiencia de duelo, un cara a cara con la muerte o la intemperie, sino que tiene además el alcance performativo que, en su resonancia, llega al lector. En ese sentido, la lectura que hace Idelber Avelar (siguiendo también la obra señera de Walter Benjamin), para caracterizar como alegorías a las producciones ficcionales latinoamericanas más significativas de la dictadura resulta pertinente, pues nos habla del valor que posee la literatura en tanto huella o ruina. La alegoría sostendría a la experiencia al enrostrar una imposibilidad, dicha imposibilidad no es otra que el desfondamiento, la experiencia del vacío, de la muerte:

Sólo hay alegorías de pérdidas, el duelo por la pérdida es lo que funda el imperativo alegórico. Relación irreductible, entonces, entre alegoría e imposibilidad: alegoría es todo aquello que representa la imposibilidad de representar. El objeto de la alegoría sólo se ofrecería al conocimiento, por definición, como objeto perdido, objeto en retirada. Sólo en relación con este objeto perdido -lo imposible ya no rescatable como objeto pasible de afirmación- la ficción postdictatorial vislumbraría el suelo que la constituye y circunscribe, y sobre el cual ella misma se sostiene, el suelo del olvido (Avelar, 2000: 226- 227).

Así, la experiencia estética se presentaría como una experiencia de "extrañamiento" que exige una labor de recomposición y readaptación por parte del lector, labor que nunca es conclusiva, sino que por el contrario se mantiene inexorablemente abierta. Dicha condición constitutiva se puede apreciar en Prosa del Otoño en Gerona, en tanto que el poema se propone como una instancia estética, productiva y receptiva, que a través del procedimiento del shock abre las posibilidades de consideración vital, paradójicamente, al enrostrar los límites de nuestra condición humana, su precariedad y permanente productividad.

\section{Referencias}

Avelar, Idelber. (2000). Alegorías de la derrota: la ficción postdictatorial y el trabajo del duelo. Santiago: Editorial Cuarto Propio.

Bachelard, Gastón. (1965). La poética del espacio. México: Fondo de cultura económica. 
Bauman, Zygmunt. Modernidad líquida. México: Fondo de cultura económica, 2002.

Benveniste, Émile. (1971). "De la subjetividad en el lenguaje”. Problemas de lingüística general. México: Siglo veintiuno editores.

Bolaño, Roberto. (1997). “Sensini”. Llamadas telefónicas. Barcelona: Anagrama.

. (2000). "Prosa del otoño en Gerona”. Tres. Barcelona: Acantilado.

. (2007). "Prosa del otoño en Gerona". La Universidad Desconocida. Barcelona: Anagrama. . (2007). "Gente que se aleja". La Universidad Desconocida. Barcelona: Anagrama. 2007.

Bolaño, Roberto. Cuadernos Hispanoamericanos Vol. 604. 2000. 64.

Heidegger, Martín. (2006). "Hölderin y la esencia de la poesía" 1916. Arte y Poesía. México: Fondo de cultura económica.

Oyarzún, Pablo. (2008). "Nota preliminar”. Charles Baudelaire. El Spleen de París. Santiago: Editorial Lom.

Perec, Georges. (2012). Un hombre que duerme. Madrid: Editorial Impedimenta.

Sloterdijk, Peter. (2014). Esferas I: Burbujas. Microsferología. Vol. 24. Siruela.

Trigo, Abril. (2000). "Migrancia: memoria: modernidá”. Nuevas perspectivas desde/sobre América Latina. Mabel Moraña, editora. Santiago: Editorial Cuarto propio, 2000.

Vattimo, Gianni. (1990). "El arte de la oscilación”. La sociedad transparente. Barcelona: Ediciones Paidós. 